\title{
NALTREXONE ASSOCIATED SEIZURE: A CASE REPORT
}

\section{Pharmacology}

\section{Rajdip Barman*}

\section{Pradipta} Majumder
MD Attending Psychiatrist \& Vice-Chair, Genesis Behavioral Health, Davenport, Iowa, USA.*Corresponding Author

\section{Varun Sharma}

\author{
MD Attending Psychiatrist, WellSpan Philhaven, York, Pennsylvania, USA.
}

\section{ABSTRACT}

Naltrexone is an opioid antagonist prescribed to treat opioid use disorder and as an anti-craving medication for alcohol use disorder. Gastrointestinal side effects are considered the most common, and liver damage is a serious and rare side effect of naltrexone. In this case report, we describe a 40-year-old patient who developed a seizure after initiating treatment with naltrexone. Although the mechanism is not clear as naltrexone is not a well-known pro-convulsant medication, a few hypotheses for association with seizure have been postulated based on the studies on opioid agonists and similar opioid antagonist naloxone. Based on this case report, we strongly recommend that clinicians should thoroughly assess the risk factors for seizures in patients before using naltrexone and start long-acting injectable naltrexone only after an adequate trial of oral naltrexone to minimize the risk of seizure.
\end{abstract}

Attending Psychiatrist, Dover Behavioral Health Systems, Dover, Delaware, USA

\section{KEYWORDS}

Naltrexone, Alcohol Withdrawal, Seizure, Convulsion, Adverse Reaction

\section{INTRODUCTION:}

Naltrexone is a non-selective opioid antagonist with the highest affinity for mu-opioid receptors and exerts its action in the reward pathway associated with alcohol. ${ }^{[1]}$ U.S. Food and Drug Administration (FDA) approved oral naltrexone for opioid dependence in 1985 and alcohol dependence in $1994 .{ }^{[2]}$ Naltrexone is clinically used as an anti-craving medication for alcohol use disorder and relapse prevention following opioid detoxification. ${ }^{[3,4]}$ Significant improvements with controlled drinking, reduction of alcohol craving, delaying relapse, and improvement of liver enzymes with naltrexone have been elicited in several studies ${ }^{[5,6]}$ Long-acting sustained-release Naltrexone has been developed to avoid the risks of non-adherence and minimizing gastrointestinal (G.I.) side effects of oral preparation, which maintain therapeutic blood concentration for 4 weeks; and also, a subcutaneous form which maintains blood naltrexone for 4-6 months. ${ }^{[7,8]} \mathrm{A}$ few common and significant side effects of naltrexone are nausea, vomiting, headache, dizziness, anxiety, somnolence, and liver damage, ${ }^{[9]}$ but naltrexone induced seizure is not well documented. We describe a case in which naltrexone precipitated seizure in a person who was otherwise medically stable.

\section{Case Report:}

A 40-year-old female with a history of bipolar mood disorder type 2 and alcohol dependence was admitted to the adult psychiatric unit with suicidal ideations. Recent loss of job secondary to restrictions imposed by the casino authority to prevent transmission of COVID-19 (Coronavirus disease 2019), loss of medical insurance, financial stressors, and being away from her children were the major precipitating factors for the current episode of depression. She endorsed symptoms of clinical depression such as loss of energy, motivation, hopelessness, helplessness, loss of sleep, poor appetite, and attempted to cut her neck and left forearm before admission. She denied any recent symptoms of mania, hypomania, or psychosis.

Previously she had several episodes of depression and hypomania, was admitted to psychiatric hospitals and had trials of several psychotropic medications. History of suicide attempt by overdosing on pills raised the safety concerns resulting in current hospitalization. She also had a long history of alcohol dependence, started drinking alcohol in early adulthood, and had relapses until she was sober for 2 years before a recent relapse 2 months ago. She was drinking wine 4 glasses every day, and the last drink was on the day of admission. The alcohol level was 279 in the emergency department, and the urine drug screen was negative for illicit substances. At the time of admission, she didn't have any symptoms related to COVID- 19, was medically stable, and routine lab works such as complete blood count, electrolytes, liver function, renal function, TSH (Thyroid stimulating hormone), Li levels were within normal limits. CT brain was done as she complained of severe headaches, and there was no significant finding.
During this hospitalization, escitalopram was increased up to $15 \mathrm{mg}$ daily to address depression. She was continued on home medications Lithium $600 \mathrm{mg}$ two times a day, Quetiapine $100 \mathrm{mg}$ at night, and gabapentin $300 \mathrm{mg}$ three times a day for neuropathic pain. Lorazepam was tapered off gradually to address alcohol withdrawal symptoms. Initially, for the first 3 days, she had mild to moderate tremors in the upper extremities, mild diarrhea, and lower abdominal pain that gradually resolved without any other significant alcohol withdrawalrelated complications. Oral naltrexone $50 \mathrm{mg}$ daily was started as an anti-craving medication. After 7 days of hospital stay, she reported significant improvement in mood and resolution of suicidal ideations. She was discharged with outpatient follow up with a psychiatrist, therapist, substance abuse treatment program, and she showed interest in attending the alcoholic anonymous meetings as well. After 6 days of discharge, she called the unit and reported that she had generalized convulsion that lasted for 20-30 seconds with clenching of teeth and a brief period of post-ictal confusion. She could recall a history of seizure when she had a trial of naltrexone in the past but denied any long-standing history of a seizure disorder. Upon neurological evaluation, physical examination was noncontributory. The routine lab works, such as complete blood count; complete metabolic panel, were within normal limits. Urine toxicology and blood alcohol level were negative. EEG (Electroencephalogram) and brain computed tomography scan were nonsignificant as well. As there was a clear correlation of seizure with naltrexone, the medication was discontinued immediately, and she did not report any further episodes of seizure in 4 months following discharge.

\section{DISCUSSION:}

In severe cases of alcohol withdrawal, seizure and delirium tremens are the most concerning consequences, but in our patient, the seizure was unlikely from alcohol withdrawal after 2 weeks of the last drink in the context of completing the alcohol detox in an inpatient setting. ${ }^{[10]}$ The possibility of association of seizure with dose increment of escitalopram was ruled out as she had a similar episode in the past what resolved after stopping naltrexone. There is not much evidence on naltrexone associated seizures; however, in a study based on the WHO adverse drug reactions database, naltrexone induced seizure consisted of $2.5 \%$ of all the side effects of the naltrexone. ${ }^{[11]}$

High dose morphine and other analgesics induce convulsions in various species, including humans. ${ }^{[12]}$ On the contrary, low dose analgesics can be anticonvulsant or pro-convulsant depending on affinity, intrinsic efficacy at the opioid receptors, or alterations in the brain function. ${ }^{[13]}$ The majority of the studies on the effect of narcotic analgesics in epileptiform activities have been done on morphine and have shown that the inhibitory effect on seizure activity is mediated by mu receptors and excitatory activity by kappa ${ }^{[14]}$ Research on the mechanism of naltrexone induced seizure is limited. Nevertheless, 
naloxone was studied to precipitate seizures in rats because of kappa receptor antagonism. The other possible mechanism for increasing the risk of seizures might be mediated by blocking the endogenous muopioid receptors. The addition of our case to the literature may be useful for the clinical practice since the evidence of naltrexone associated seizure is limited. Seizure as an adverse reaction also raises the requirement of a thorough evaluation of risk factors and administration of the oral naltrexone before using the long-acting form.

Declaration of patient consent: No patient identifying information has been mentioned in the case report.

\section{Financial support and Sponsorship: None}

\section{Conflict of Interest: There is no conflict of interest}

\section{REFERENCES:}

1. Latt NC, Jurd S, Houseman J, Wutzke SE. Naltrexone in alcohol dependence: a randomized controlled trial of effectiveness in a standard clinical setting. Med J Aust 2002;176:530-4.

2. Weinrieb RM, O'Brien CP. Naltrexone in the treatment of alcoholism. Annu Rev Med 1997; 48:477-87.

3. Spanagel R, Vengeliene V. New Pharmacological Treatment strategies for relapse prevention. Curr Top Behav Neurosci 2013;13:583-609. doi: 10.1007/7854 2012205.

4. DeMartini KS, Foster DW, Corbin WR, Fucito LM, Romano D, Leeman RF et al. Drinking goals and attainment in a naltrexone trial of young adult heavy drinkers. J Drinking goals and attainment in a naltrexone trial of young adult heavy drinkers. J

5. Kranzler HR, Van Kirk J. Efficacy of Naltrexone and Acamprosate for alcoholism treatment: a meta-analysis. Alcohol Clin Exp Res 2001;25:1335-41.

6. Carmen B, Angeles M, Ana M, Maria AJ. Efficacy and safety of naltrexone and acamprosate in the treatment of alcohol dependence: a systematic review. Addiction 2004; 99:811-28.

7. Garbutt JC, Kranzler HR, O'Malley SS, Gastfriend DR, Pettinati HM, Silverman BL et al. Efficacy and tolerability of long-acting injectable Naltrexone for alcohol dependence: a randomized controlled trial. JAMA 2005;293:1617-25.

8. Ngo HTT, Arnold-Reed DE, Hansson RC, Tait RJ, Hulse GK. Blood naltrexone levels over time following naltrexone implant. Prog Neuropsychopharmacol Biol Psychiatry over time following naltrexone implant. Prog Neuropsychopharmacol Biol Psychiatry
2008;32:23-8.

9. Pfohl DN, Allen JI, Atkinson RL, Knopman DS, Malcolm RJ, Mitchell JE et al. Naltrexone hydrochloride (Trexan): a review of serum transaminase elevations at high dosage. NIDAResearch Monograph 1986;67:66-72.

10. Swift RM. Drug therapy for alcohol dependence. N Engl J Med 1999;340(19):1482-90

11. Kumlien E, Lundberg PO. Seizure risk associated with neuroactive drugs: Data from the WHO adverse drug reactions database. Seizure 2010;19(2):69-73.

12. Reisine T, Pasternak GW. Opioid analgesics and antagonists. In: Hardman JG, Limbird LE, editors. Goodman \& Gilman's: The Pharmacological Basis of Therapeutics (ed 9) New York, NY: McGraw-Hill; 1996. pp. 521-56.

13. Frenk H. Pro- and anticonvulsant actions of morphine and the endogenous opioids: Involvement and interactions of multiple opiate and non-opiate systems. Brain Res. Rev $1983 ; 6: 197-210$

14. Yousef P, Ehsan S, Rassoulia A, Sadeghi-Hashjina G, Roshan-Milanic S, Derafshpourb $\mathrm{L}$ et al. The effect of selective opioid receptor agonists and antagonists on epileptiform activity in morphine-dependent infant mice hippocampal slices. Int J Dev Neurosci 2017;60:56-62.

15. DeMartini KS, Foster DW, Corbin WR, Fucito LM, Romano D, Leeman RF et al. Drinking goals and attainment in a naltrexone trial of young adult heavy drinkers. $\mathrm{J}$ Consult Clin Psychol 2018:86(9):765-74.

16. Marylou VS, Russell A, Janie B, Julie CL, George FK. Kappa opioid control of seizures produced by a virus in an animal model. Brain 2006;129:642-54. 